\title{
Using Mobile Computing and Information Technology in Civil Engineering Construction Projects
}

\author{
M.N. Jadid ${ }^{* 1}$ and M.M. Idress² \\ ${ }^{1}$ Department of Building Science \& Technology - University Campus Projects, General Supervisor for the University Campus \\ Projects, P.O. Box 30973, Alkhobar 31952 - Saudi Arabia \\ 2 University Campus Projects - IT Consultant, P.O. Box 1982, Dammam, Saudi Arabia
}

Received 1 December 2003; accepted 14 April 2004

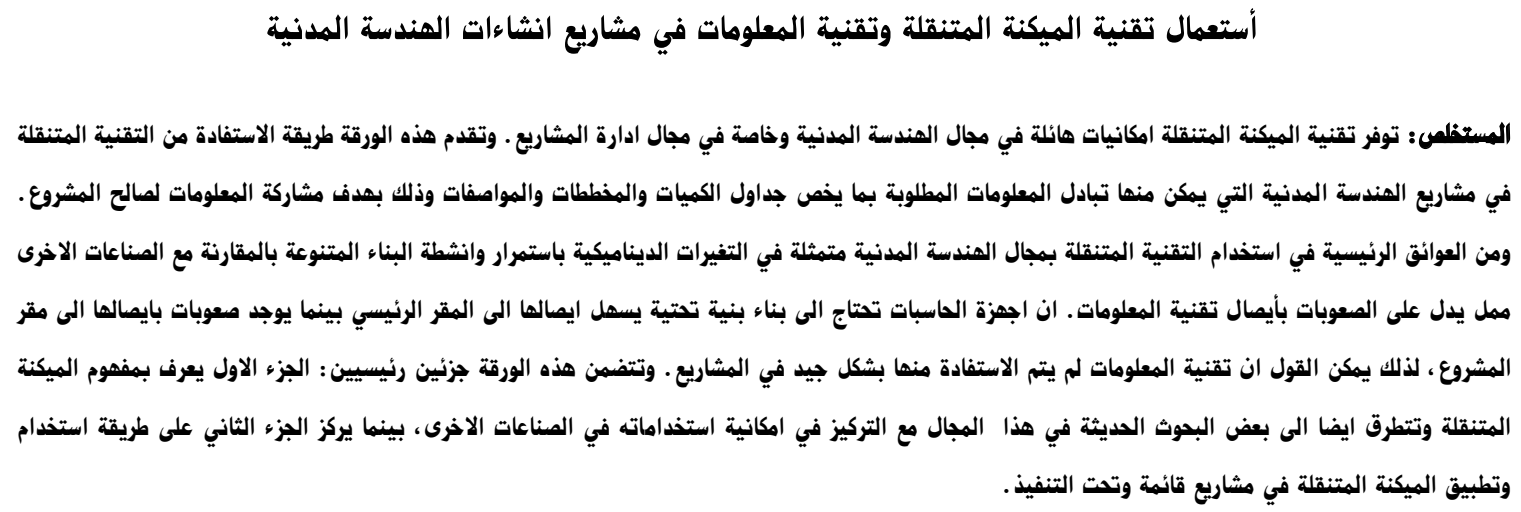

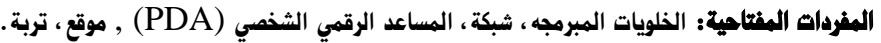

\begin{abstract}
Mobile computing technology has an enormous potential in civil engineering, mainly in the field of construction management. This paper presents an approach by using mobile computing in a civil engineering construction project, exploring how information can be exchanged at a construction site, and how billing of quantities (BOQ), drawings and specifications are shared for the benefit of the project. One of the major obstacles in using information technology (IT) when applied to civil engineering is due to the dynamic changes in the construction activities and the diversity of construction methods as compared to other industries. This has proved to be a great disadvantage when trying to give construction sites adequate IT support. Computers require infrastructure, which can be transferred easily to the head office, but rarely to the construction site itself in a systematic way. Therefore, the impact of IT on the way the construction industry actually works has not been significantly utilized. This paper consists of two main parts. The first part defines the concept of mobile computing, describes some recent research, and stresses the potential for the construction industry. The second part is focuses on an approach, implementing mobile computing in a real construction site.
\end{abstract}

Keywords: Mobile computing, Networking, Personal digital assistant (PDA), Site, Soil.

\section{Introduction}

Generally, the impact of most research results in the field of construction shows that IT has not had a significant impact on the construction industry as noted by some authors Amor et al. (2002). Most construction IT solutions such as integrated building models, including complex modular and process models, require highly organized and standardized project environments, which are not found in real-life construction projects. Partners in a construction project consortium are typically at very dif-

*Corresponding authors E-mail: mnjadid@yahoo.com ferent levels of organization and IT use. Therefore, they are forced to use mutual digital communication at quite a low level. Typically, isolated IT solutions which did have a tremendous impact on the construction industry such as e-mail and telefax machines connected at different sites, made it possible to quickly share drawings, specifications and other documents needed in a technical environment during the cycle of a construction project. The widespread use of mobile phones was another IT solution which made it possible to reach nearly anywhere at any time, thus, providing significant support for an undisturbed flow of information, but once again with an automation level of nearly zero, unfortunately. During the past few years, another device has evolved to a mature level - the handheld per- 
sonal computer (HPC), or personal digital assistant (PDA) which is often resorted to. Its speed, memory capacity, communication possibilities, reliability, small size and long power independence, as well as its level of hardware and software standardization gives the PDA a powerful potential in the information chain of a construction project at the site. However, it does not operate on an isolated individual level, but rather in an integrated and systematic way, which means an organized combination of PDAs, mobile phones providing wireless data transmission, and network-based document management.

\section{An Overview of the Wireless Lan and Mobile Computing}

Wireless LAN based mobile computing enables users to establish and maintain a wireless network connection throughout or between buildings, without the limitations of wires or cables Gast, (2003). With a WLAN, the covered area is analogous to a standard local area network. This might be a building or a campus environment, or even a small office or home environment. In large applications, by deploying a series of access points throughout a building or campus, you can achieve full coverage, providing the benefits of high-speed data rates, the freedom of mobility, and the ability to access broadband data anywhere within the local area network. Wireless LAN- solutions are becoming quite prevalent in many horizontal applications in the construction, general office and vertical industries, such as health care, manufacturing, universities and retail. Here are important but introductory facts about wireless LANs:

* Most wireless LANs operates in multiple frequency ranges - unlicensed 902-928 ISM (industrial, scientific and medical) band, unlicensed $2.4 \mathrm{GHz}$ band and licensed 18-23 GHz band.

* IEEE 802.1x delivers a centrally managed, standardsbased, and open wireless network security scheme. In addition, the EAP framework is extensible to wired networks, enabling an enterprise to use a single security architecture for every access method

* There are two technologies used in wireless LANs: direct sequence (DS) coding or frequency hopping (FH).

* Key hardware components of a wireless LAN are a wireless LAN adapter along with an antenna that resides in the mobile computer device (notebook or PDA) and an "Access Point" which acts as the hub and connects multiple mobile devices to a server. You can realistically support only 10-30 mobile devices per access point, depending on the network traffic.

* When the $14 \mathrm{~dB}$ antennas are added, the outdoor wireless configuration is extended to 3.5 miles at an impressive $11 \mathrm{Mbps}$ throughput. When combined with any third party $24 \mathrm{~dB}$ antenna, distances of 25 miles at 11 Mbps can be achieved.

\subsection{Network Configuration}

The access point's default configuration is as a root unit on a wired LAN. The other two possible roles, repeater unit and central unit in an all-wireless network, require specific changes to the default configuration.

\subsubsection{Central Unit in an All-Wireless Network}

In an all-wireless network, an access point acts as a stand-alone root unit. The access point is not attached to a wired LAN; it functions as a hub linking all stations

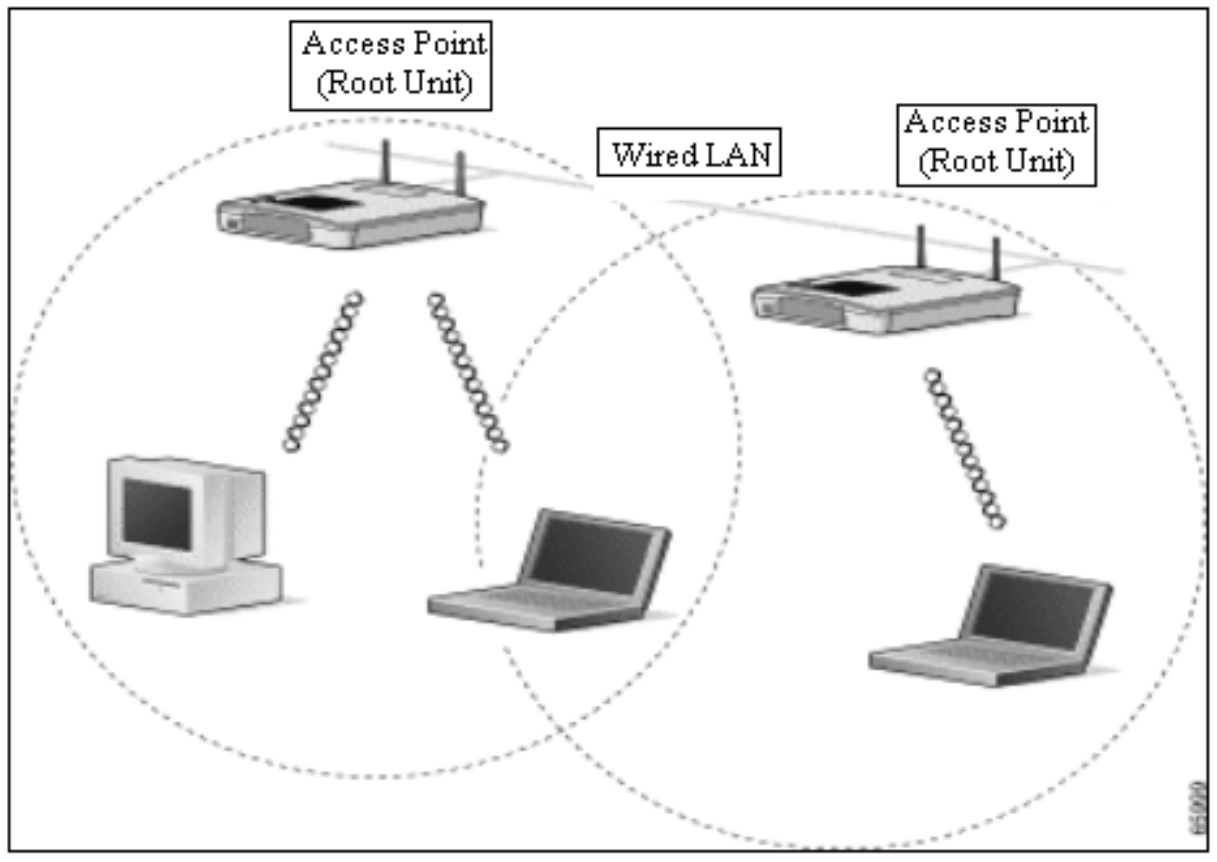

Figure 1. Base station point to point configuration (C-Spec's Web Site) 


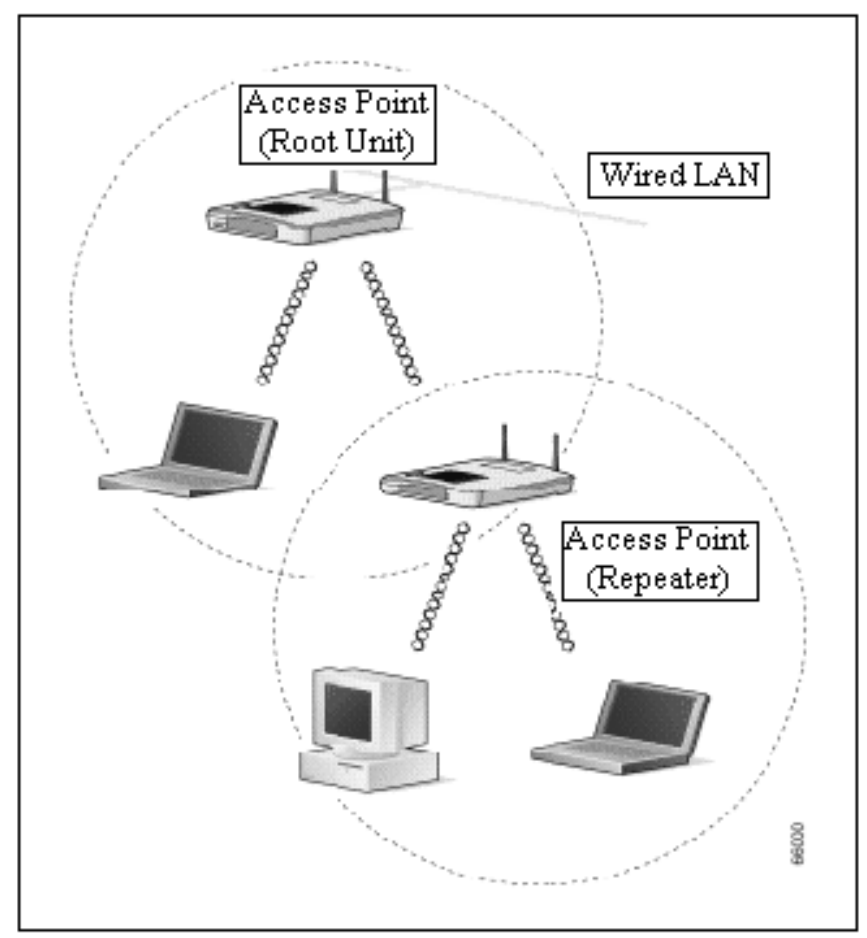

Figure 2. Use of repeater (Cisco-Aironet)

together as shown in Fig. 1. The access point serves as the focal point for communications.

\subsubsection{Repeater Unit that Extends Wireless Range}

An access point can be configured as a stand alone repeater to extend the range of your infrastructure or to overcome an obstacle that blocks radio communication (Fig. 2). The repeater forwards traffic between wireless users and the wired LAN by sending packets either to another repeater or to an access point connected to the wired LAN (Fig. 3).

\subsection{Mobile Computing Architecture}

Wireless LAN consists of a hardware access point that generates wireless signals in a specific region (Fig. 3). PDA's Wireless notebook or cellelular devices are used to access the features. A user can access text/email, text/email, Web browsing and all internet features. The IEEE 802.1x Protocol is used in this technology.

\subsection{Availability of Software and Hardware}

Mobile computing fundamentally differs from desktop computing. Mobile devices including PDAs, mobile phones and digital cameras, when compared to desktop computers have low computational power, small memory and often no mass storage. Communication links to other mobile devices or to a stationary network are usually wireless.
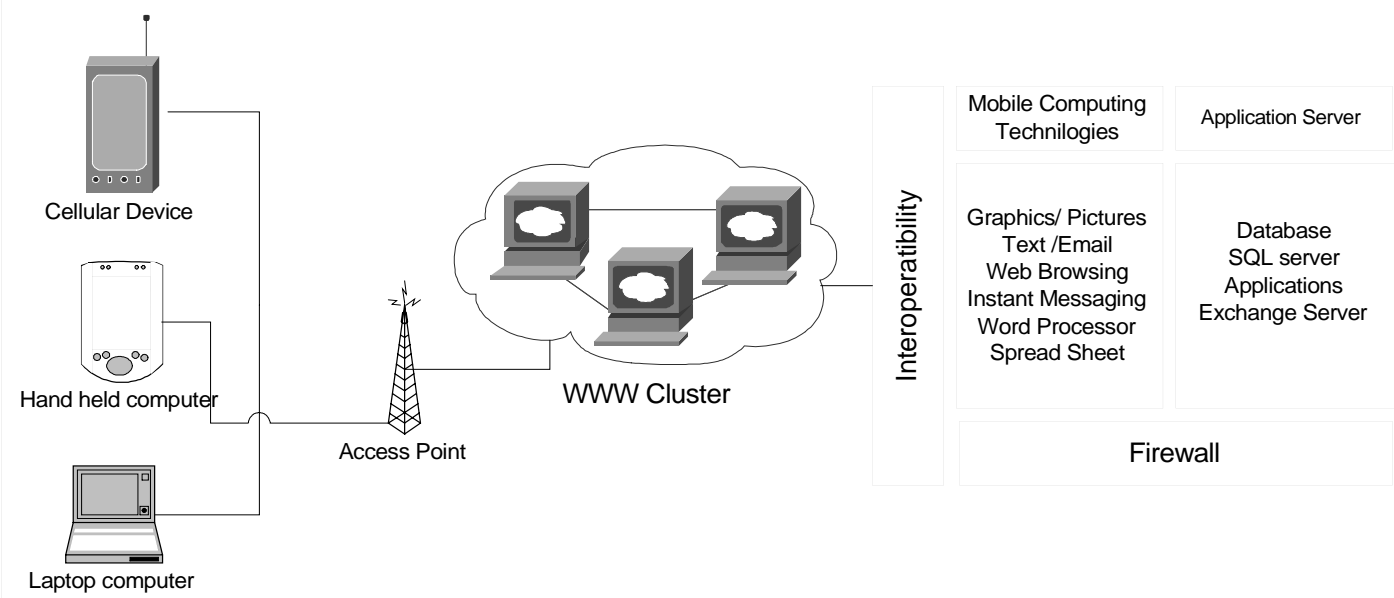

Figure 3. Mobile computing architecture 


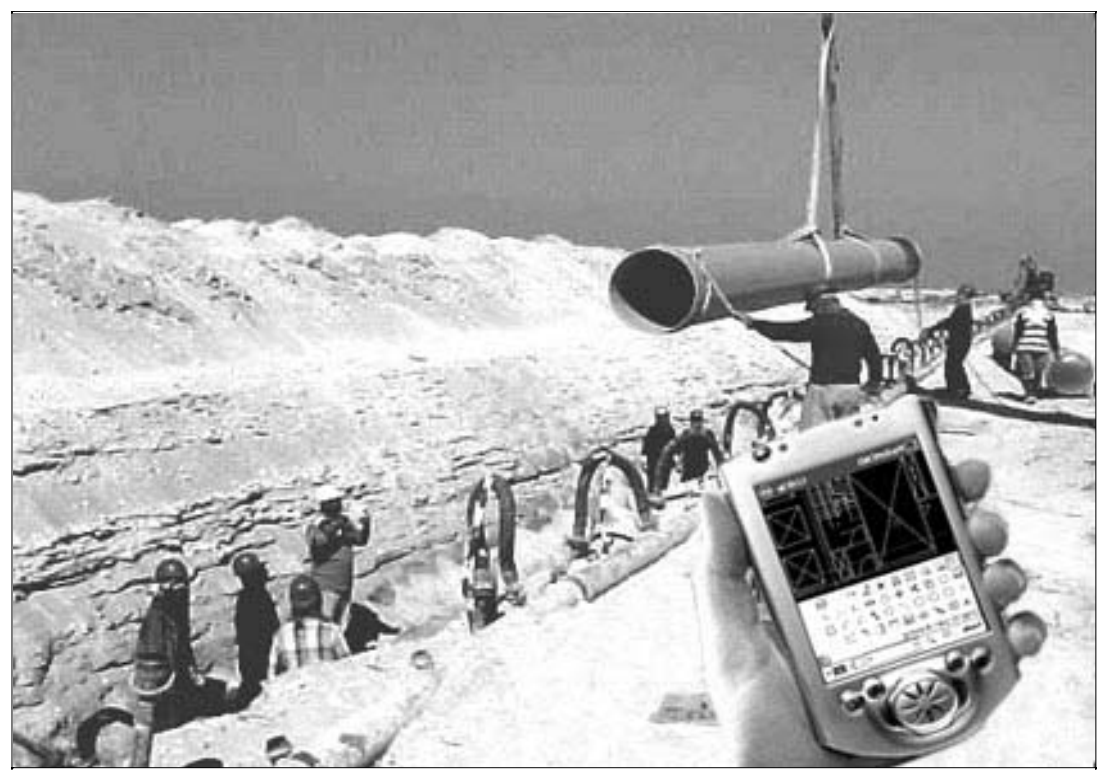

Figure 4. King Faisal University Construction Site (the foreman's equipment)

Four groups responsible for the implementation of activities in parallel are:

* Existing hardware, software and organization on site and in related offices,

* Mobile computers and suitable application software,

* Wireless communication technology (local networks, mobile phones and services),

* Project management, implementation of document management system.

\subsection{Data Formats Supported through Wireless Communication}

* Text File,

* Pictures,

* Drawing,

* Video /Multimedia.

Figure 4 shows an emulation of foreman's equipment demonstrating Mobile CAD running on PDA at King Faisal University construction site.

\subsection{General Software (CAD, PMS, GIS)}

General software includes

* Island applications,

* Wickes lumber construction-management software (ordering of material),

* SHERPA (pipling operations),

* Bidcom (recording project data),

* AirWavz,

* Job Cost.

\section{Mobile Computing in Construction Industry}

There are a number of project tasks that can be auto- mated in the construction industry - a few common examples are provided above. Some more applications are discussed in the following section.

\subsection{Site Inspection in Construction Industry}

Site inspection and project status reporting is considered as a high value mobile application by construction engineers because it reduces the number of site visits by supervising engineers by half or greater. While the construction industry has been slow in adopting mobile computing and automation in the field, things are changing quite fast now, since low-cost handheld devices are available and several construction automation applications have been developed by vendors.

\subsection{Impact of Changes of Site Locations}

It is a fact that the locations of construction sites frequently change which can cause a delay in collecting data from the field, and therefore produces a great need and importance for mobile computing. The field client not only collects data, but it also provides information to the progress engineer. The annual report by Daito (2000) mentioned four main benefits of the system:

* It eliminates redundancy in project task operations,

* Reduces the response waiting time,

* Greatly limits revision of job tasks,

* Enables access to new construction standards.

But, how many companies working together on a construction project would be able to follow this approach? It becomes evident that standard devices and services have to be available on the market at affordable prices in order to be attractive.

Special devices that could be highly applicable to construction activities include all the necessary input and out- 


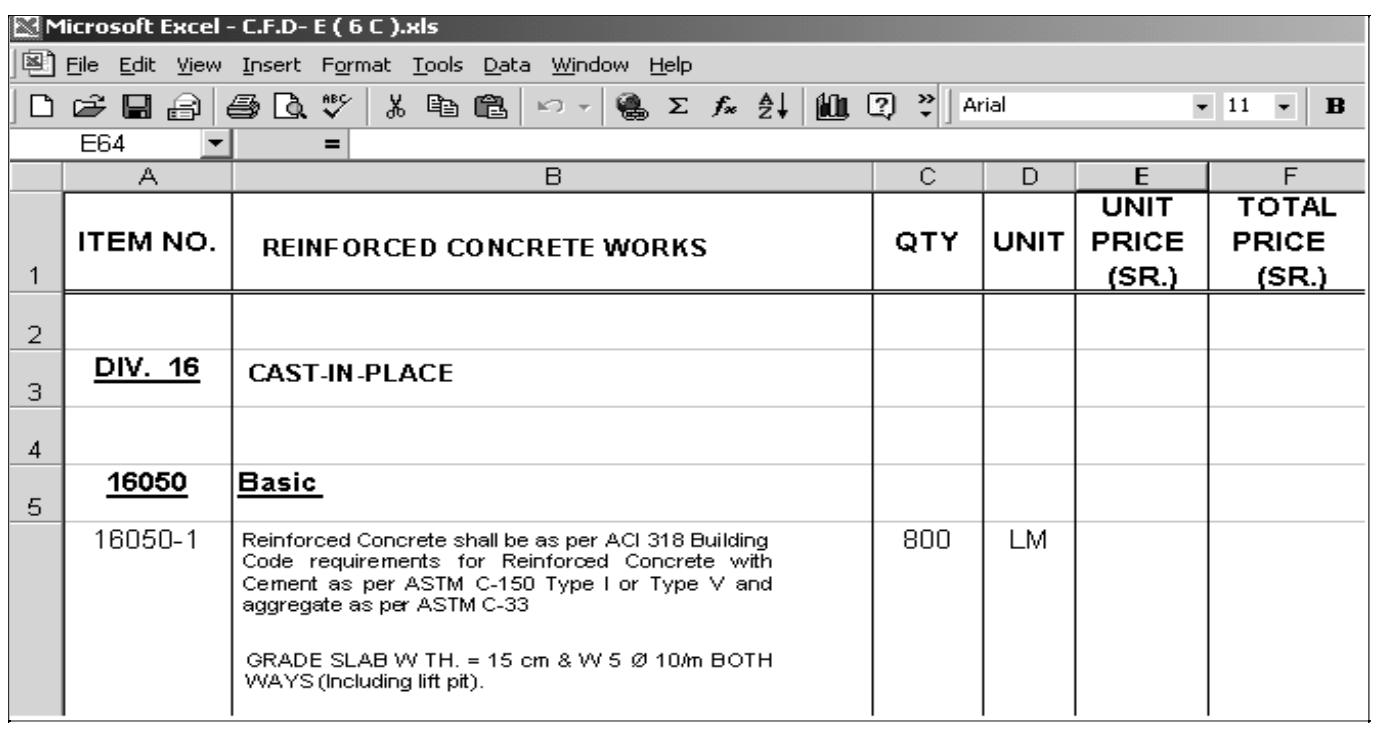

Figure 5. Daily activity plan (Bill of Quantities-BOQ), Excel \& Pocket Excel sheet

put devices where the user's hands are left free Xybernaut, (2000) (Fig. 5). The difficulty of controlling mobile computers by voice, which is also a requirement for wearable computers, has excited the interest of some researchers. In the field of civil engineering there are two interesting reports, one dealing mostly with inspection-oriented applications Garrett, (2000), and other focusing on navigation through drawings Reinhardt and et al. (2000).

\subsection{Construction Industry Applications}

* Dispatch of construction crew to a job site,

* Project status monitoring and reporting,

* On-site estimation of small jobs,

* Scheduling of construction equipment like graders, trucks, etc.,

* Ordering of rental equipment to meet sudden demands,

* Transfer of equipment from one site to another,

* Tracking of labour time spent and the material used for cost plus projects,

* Crew card automation and transmittal through wireless networks.

\section{Mobile Use at a Construction Site}

The new site for the King Faisal University (KFU) campus in Dammam, Saudi Arabia is located on the coast between cities of Dammam and Alkhobar. These two developing cities along with Dhahran city are expected to evolve into a single integrated urban complex that will be the administrative and industrial center of the Eastern Region of Saudi Arabia. The total area of the campus is about $3,000,000 \mathrm{~m}^{2}$ and will be constructed in several phases. The total building area at the completion of the contract is about $570,000 \mathrm{~m}^{2}$. The new campus will accommodate male and female students in two distinct areas. Each area will carry its own educational facilities, public services and housing.

The main campus is divided into five main areas as shown in Fig. 6 while Table 1 shows the subdivision for each area. This division was made in order to acquire an efficient outcome in mobile computing at this construction site. With mobile computing, engineers, architectures, technicians and workmen can take advantage by means of timely and targeted information. The jobs can transmit through a fast medium like wireless devices to a particular engineer or technician, as well as collect data or daily

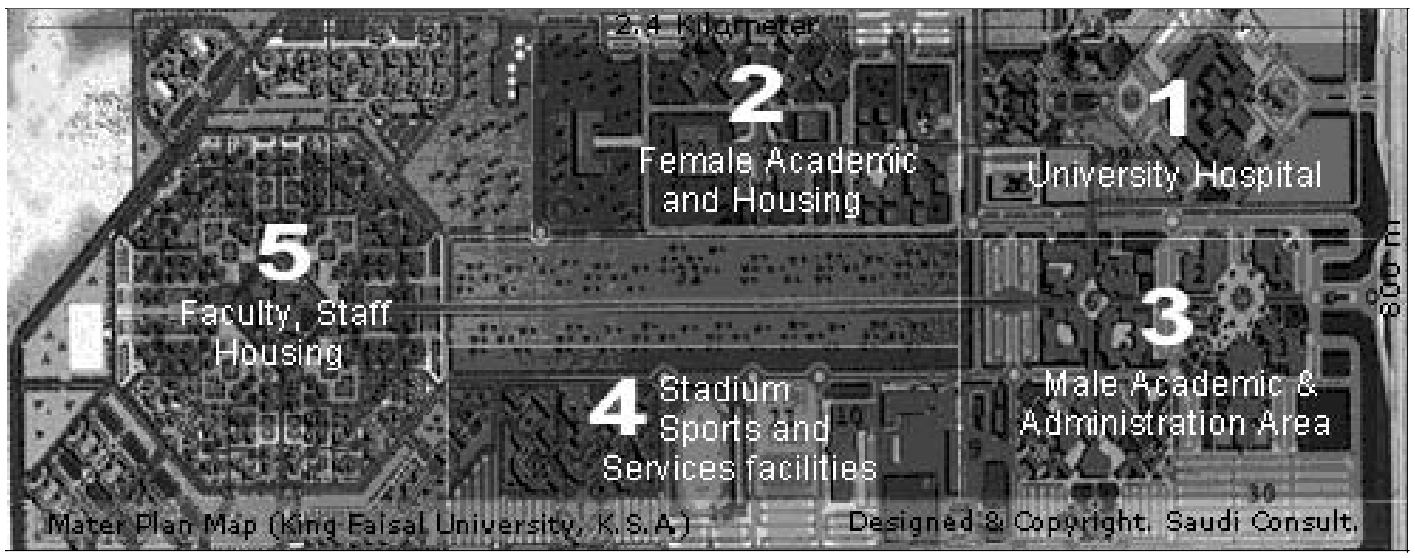

Figure 6. Master plan for King Faisal University (Divided into five main areas) 
Table 1. Colleges and facilities within the areas

\begin{tabular}{|c|c|}
\hline \multicolumn{2}{|l|}{ 1. Main Hospital Area } \\
\hline Main Hospital & The Psychiatric Center \\
\hline The Rehabilitation Center & The Dental Clinic \\
\hline The Nurses’ Resident & The Mosque \\
\hline \multicolumn{2}{|c|}{ 2. Female Medical Center and Administration } \\
\hline College of Medicine & College of Dentistry \\
\hline College of Applied Science & College of Nursing \\
\hline Basic Science College & Administration Building \\
\hline $\begin{array}{l}\text { Food Services, Telephone and } \\
\text { Telecommunication Building }\end{array}$ & Female Housing and Activity Center \\
\hline \multicolumn{2}{|c|}{ 3. Male Medical Center and Administration } \\
\hline College of Medicine & College of Dentistry \\
\hline College of Applied Science & College of Nursing \\
\hline Basic Science College & Administration Building \\
\hline $\begin{array}{l}\text { Food Services Telephone and } \\
\text { Telecommunication Building }\end{array}$ & Male Housing and Activity Center \\
\hline \multicolumn{2}{|c|}{ 4. Sports Area and the Utility Building } \\
\hline Student Housing & Open Sports Facilities \\
\hline Closed Sports Facilities & Open Sports Fields \\
\hline Utility Building & Stadium \\
\hline \multicolumn{2}{|l|}{ 5. Housing } \\
\hline Married Faculty Housing & Unmarried Faculty Housing \\
\hline Married Staff Housing & Married Student Housing \\
\hline
\end{tabular}

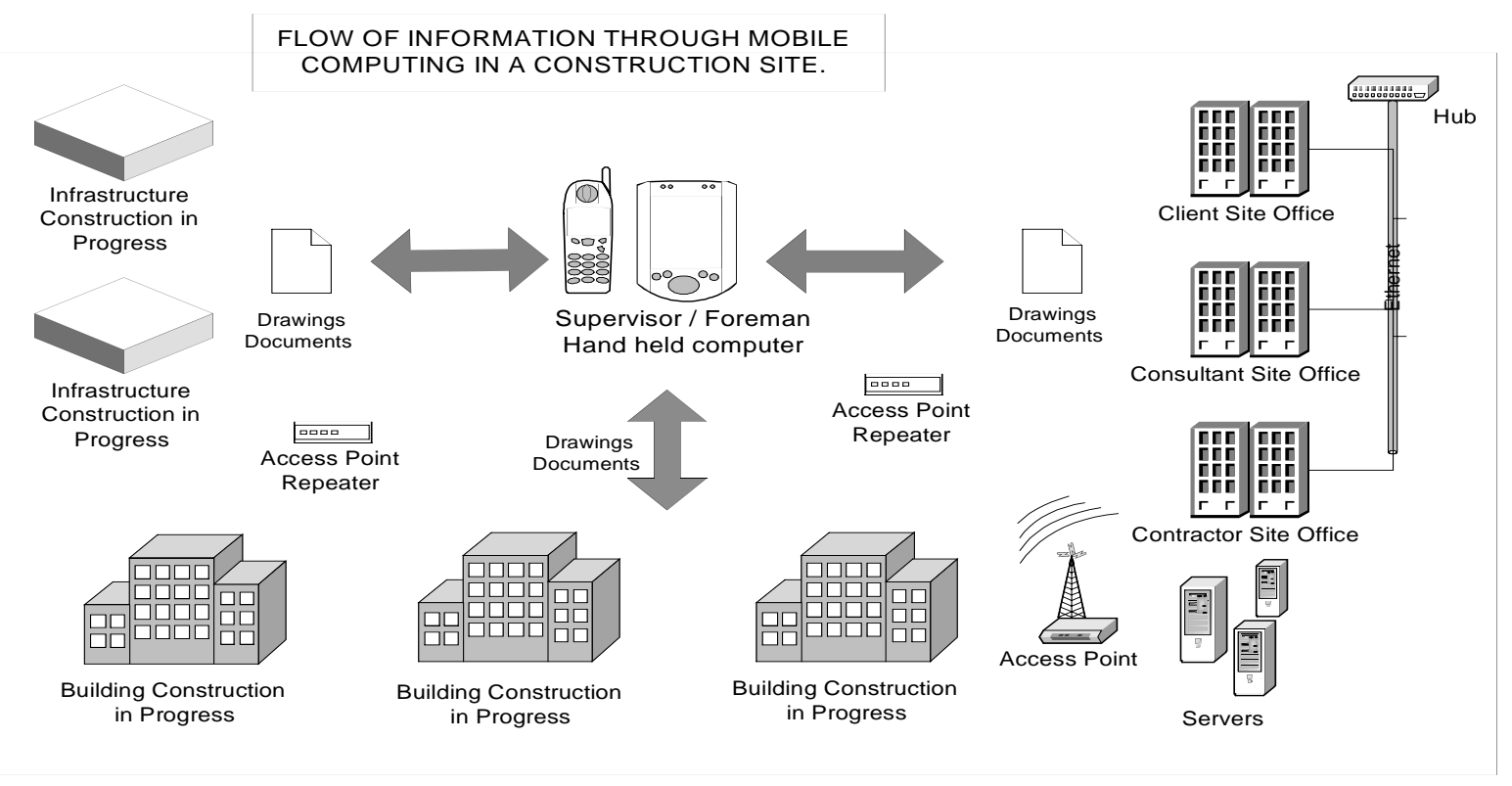

Figure 7. Logical flow of information suggested at the KFU construction site 
reports from the field. The mobile computing technique can be used effectively in civil engineering in general.

\subsection{Infrastructure and Buildings Site Conditions}

The preliminary geotechnical consultant's report (Saudi Services Consultant, 2001) has revealed that the soil is very loose to loose, silty sand up to minimum of $4.0 \mathrm{~m}$ depth, followed by dense to very dense, silty sand up to $12 \mathrm{~m}$. The resulting sub-grade shall be compacted by a heavy vibratory roller to a minimum of $70 \%$ of the relative density for cohesionless soil or to a minimum of $95 \%$ of modified proctor density for cohesive and well-graded soil. The recommended fill by the designer should be placed in layers not exceeding $300 \mathrm{~mm}$ each and compacted according to the type of material used. The above information revealed that the soil condition for the site is poor therefore soil treatment is recommended by the consultants.

The scope of the infrastructure and buildings for the site includes but not limited to:

* Excavation and backfilling including slope protection,

* Roads and parking that requires base course, asphalting marking and signage,

* Walkways, curbs and gutters,

* Storm water drainage,

* Water, sewer, irrigation and chilled water networks,

* Electrical network and lighting systems,

* Sewer and storm pump stations,

* Reverse osmosis (RO) plant,

* Sewage treatment plant,

* Hospital, Academic buildings, administration, housings, sport areas and the utility building.

To overcome these shortcomings of the site conditions, an approach was suggested to provide mobile communication in order to utilize the flow of information between the client, consultant and the contractor effectively.

The main approach proposed consists of the following tasks:

* Exploring the characteristics and potential of commercially available hand held devices for the construction industry,

* Evaluating the use of Wifi or blue tooth technology with Palms for data transmissions at the construction project site,

* Ensuring flow of information among King Faisal University supervisors, consultants, contractors and the engineers at the construction site,

* Providing a document management system for mobile computing, transfer of text, drawings and spreadsheets through the software of latest hand held devices.

The logical flow of the suggested information is shown in Fig. 7, which represents the mobile computing works in construction process at the KFU site.

\section{Conclusions}

Construction management can be achieved by using current mobile computing and web services. Their full potential has not been utilized and there are rooms for improvement expected in the future.

The commercially available PDAs already offer abundant functionality and processing speed, however, suitability under stress conditions like dust, strong light, rain, which is normal at a construction site, is another problem which needs to be addressed seriously in the future. There is also the ever-present problem of screen size: either the screen is too small for a good information overview, or too big to fit in a pocket. It is clear that devices not fitting into a foreman's pocket will not be carried around, but rather left back at the site office.

Utilizing the latest in mobile computing at the construction site will provide innovation and customized solutions which would allow individuals in the construction site to maximize the efficiency when collecting data and accessing important information.

\section{Acknowledgments}

The authors express their sincere thanks to King Faisal University for providing the necessary data and information.

\section{References}

Amor, R., Betts, M., and Coetzee, G., 2002, “Information Technology for Construction: Recent Work and Future Directions,” ITcon 17: pp. 245-258.

Daito Trust Construction Co. (2000), Annual Report, http://www.kentaku.co.jp/e/tcs/.

Garrett, J.H., Buergy, C., Reinhardt, and Sunkpho, J., 2002, "An Overview of the Research in Mobile/Wearable Computer-Aided Engineering Systems in the Advanced Infrastructure Systems Lab at Carnegie Mellon University," In the CD Proceedings of the BAUEN MIT Computern (Computer-Aided Construction) conference, Bonn, Germany, April 11-12, 2002.

Matthew, S. and Gast, 2003, "802.11 Wireless Networks: The Definitive Guide," (O'Reilly Networking).

Reinhardt, J., Garrett, J.H. and Scherer, J., 2000, "The Preliminary Design of a Wearable Computer for the Supporting Construction Progress Monitoring," Internationales, Kolloquium Uber die Anwedung der informatik under Mathematik in Architecture und Weimar, Germany, June 2000.

Saudi Consulting Services, 2001, King Faisal University Permanent Campus, Soil Report, Saudi Arabia.

Xybernaut wearable computers. Www.xybernaut.com/ 